\title{
Gestão estratégica multicultural baseada no Balanced Scorecard em instituições de ensino
}

Saul Eliahú Mizrahi*

Alberto G. Canen**

\section{Resumo}

Este artigo apresenta os fundamentos para a construção de uma proposta de gestão estratégica para escolas de Ensino Básico com princípios do Balanced Scorecard em uma abordagem multicultural, consolidando um conjunto integrado de procedimentos e recomendações metodológicas, de modo a promover a valorização da diversidade cultural para o sucesso escolar. Para atingir este objetivo, buscou-se identificar e analisar elementos que facilitam ou dificultam a gestão nesta perspectiva. As vantagens encontradas neste trabalho são seu foco na melhoria institucional, proporcionando maior comunicação entre as partes. Apoia, assim, a realização dos objetivos de democratização da gestão do ensino.

Palavras-chave: Educação básica. Planejamento estratégico. Balanced Scorecard. Multiculturalismo.

\section{Multicultural strategic planning based on Balanced Scorecard in teaching institutes Abstract}

This paper presents the basis of a multicultural approach for the construction of a strategic planning policy proposal for Basic Education schools based on Balanced Scorecard principles, in a multicultural approach, strengthening an integrated set of procedures and methodological guidance in order to promote cultural diversity appreciation in order to obtain teaching success. To meet this goal, the elements that simplify intercultural planning or make it more difficult

\footnotetext{
* Doutor em Engenharia de Produção, COPPE/Universidade Federal do Rio de Janeiro (UFRJ); Pesquisador do Instituto Nacional de Tecnologia. E-mail: saul.mizrahi@int.gov.br

** Pós-Doutorado, University of Strathclyde; Professor do Programa de Engenharia de Produção, COPPE/UFRJ. E-mail: agcanen@pep.ufrj.br
} 
were identified, analyzed and elucidated. The advantages found in this work are the focus on institutional improvement, through an increase of multilateral communication. In this manner, this study helps to reach the democratization objectives of teaching planning.

Keywords: Basic education. Strategic planning. Balanced Scorecard. Multiculturalism.

\section{Gestión estratégica multicultural basada en el Balanced Scorecard en establecimientos de enseñanza Resumen}

Este artículo presenta los fundamentos de un enfoque multicultural para la construcción de una propuesta de gestión estratégica para escuelas de Enseñanza básica con principios del Balanced Scorecard, consolidando un conjunto integrado de procedimientos y recomendaciones metodológicas, con el objeto de promover la valoración de la diversidad cultural para obtener éxito escolar. Para alcanzar este objetivo, se buscó identificar y analizar elementos que facilitan o dificultan la gestión intercultural. Se enfocó la mejoría institucional a través de una mayor comunicación multilateral. De esta forma, el trabajo da soporte a la obtención de los objetivos de democratización de la gestión de enseñanza.

Palabras clave: Educación básica. Planificación estratégica. Balanced Scorecard. Multiculturalismo.

\section{Introdução}

A presente pesquisa foi motivada pelo problema de que visões monoculturais que não propiciam a ampla participação de seus membros, desconsiderando a diversidade cultural, reduzem as possibilidades de desenvolvimento das respectivas instituições de ensino. Para que se estabeleçam condições que permitam superar este problema, este trabalho teve como objetivo o estudo da gestão com Balanced Scorecard (BSC) aplicada a instituições de Ensino Básico, buscando-se elaborar uma metodologia dedicada à gestão estratégica participativa em uma abordagem multicultural, considerando-se as especificidades de instituições de Ensino Básico no País.

A abordagem multicultural crítica é um dos fundamentos desta pesquisa. Esta abordagem busca favorecer a elaboração de políticas e práticas que possam levar à reconstrução das identidades individuais e coletivas dos sujeitos abertas à pluralidade cultural. Incentiva o exercício da reflexão frente às raízes das diferenças, sendo compreendida como ligada à valorização da diversidade cultural e o desafio a preconceitos buscando-se entender e administrar suas fontes (CANEN; CANEN, 2005, p. 32). 
Para atingir este objetivo, buscou-se identificar e analisar elementos que facilitam ou dificultam a gestão multicultural em instituições de Ensino Básico; buscouse, ainda, analisar a relação entre o BSC e multiculturalismo, identificando-se a influência da cultura na gestão, bem como os mecanismos de comunicação considerados fundamentais nesta abordagem.

0 presente ensaio teve como finalidade promover o conhecimento dos pontos críticos da gestão estratégica. Busca-se, assim, identificar as possiveis causas de conflitos, reações ou de inação, despreparo, desmotivação e apatia, levando-se ao desperdício os melhores recursos individuais e institucionais.

A principal dificuldade sobre a avaliação dos ativos intangiveis, tomando-se como exemplo os aspectos culturais, é que estes dependem do contexto institucional e das estratégias aí desenvolvidas. Sendo assim, pode-se lançar mão do BSC como ferramenta para descrever e determinar o valor gerado por estes ativos (KAPLAN; NORTON, 2004a, p. 101), pois a avaliação de ativos intangiveis possibilita o fornecimento de informação sobre a qualidade da gestão de forma que se permita definir niveis de confiança e também conhecer a instituição para monitorar seu progresso e tomar medidas corretivas, quando necessário.

\section{Aplicação do BSC em Instituições de Ensino e suas articulações multiculturais}

Cabe destacar a contribuição pioneira que Kaplan e Norton (2004b, p. 439) relatam sobre a experiência do Sistema Escolar do Condado de Fulton (FCSS), que serve de modelo para futuras implementações do BSC no que se refere à gestão estratégica de instituições de ensino. 0 sistema escolar analisado pelos referidos autores já contava com setenta e sete escolas públicas, em dois subdistritos, no norte e no sul da cidade de Atlanta, com 70 mil alunos em 2001 - momento da implantação do BSC em todas suas escolas, definindo seus planos estratégicos. 0 distrito é reconhecido pela excelência em planejamento e gestão.

Os quatro primeiros itens observados com a aplicação do BSC no FCSS dentre os dez relatados referem-se aos indicadores relacionados ao desenvolvimento do aluno tais como: crescimento na "proporção dos alunos que cumprem ou superam as expectativas de desempenho em leitura e matemática em nível estadual"; crescimento na 'porcentagem de alunos do Ensino Médio que receberam "college credit" antes da graduação'; crescimento do desempenho "dos alunos que fizeram exame Advanced Placement" com destaque em relação à média regional"; aumento do número de alunos que fazem o "exame SAT" e o aumento da pontuação média no teste. Adicionam-se, ainda, a reduzida preocupação dos pais de alunos com questões de segurança, em comparação com a média nacional; a elevação das horas de 
voluntariado; a satisfação com a escola dos filhos acima da média nacional; inauguração das novas escolas no prazo e dentro do orçamento; disponibilidade no primeiro dia de aula, em todas as escolas, de livros-texto, equipamentos e suprimentos; elevado cumprimento do orçamento (KAPLAN; NORTON, 2004b, p. 439).

Preedy e outros (2006, p. 57) destacam a utilização de indicadores de desempenho em educação para apontar práticas mais eficientes para sua melhoria, de modo a encontrar causas e condições em que ocorrem as mudanças, com vistas a estimular e concentrar esforços para monitorar padrões e tendências, dentre outros benefícios. Assim, o BSC apresenta-se como uma ferramenta institucional para esclarecer, comunicar e gerenciar a estratégia. Permite o estabelecimento de metas individuais e de equipe, assim como alinhar sistemas de informação e sistemas de indicadores de desempenho às estratégias da organização, além de oferecer uma metodologia para o estabelecimento de remunerações, alocação de recursos, planejamento, orçamento, feedback e aprendizado estratégicos.

A junção do BSC com a perspectiva multicultural se faz possivel, por um lado, pelas diferentes formas de funcionamento da instituição para que se alcancem os objetivos estratégicos traçados em seu planejamento mais amplo. Por outro lado, a justificativa do multiculturalismo se dá pela existência, hoje, de um encontro de um conjunto de atores com diferentes características culturais, no funcionamento institucional, possibilitando-se, no dia-a-dia, harmonizar a interação destes.

O BSC propicia um processo decisório participativo e transparência, possibilitando refutar discriminações e conciliar diferenças e apoiando, assim, a caracterização de um laboratório de cooperação multicultural. O BSC propicia, ainda, o diálogo entre os diferentes atores da instituição, considerando-se a intersubjetividade, a relatividade de valores e a flexibilidade nas operações, respeitando-se as condicionantes culturais.

0 tratamento de intangiveis pelo BSC coaduna-se com os valores promovidos pelo multiculturalismo. A ligação entre as variáveis buscando-se representar as relações de causa e efeito, própria do BSC, permite que estas variáveis representem tanto aspectos tangiveis, a exemplo das medidas financeiras, como intangiveis, que pode ser o nivel de confiança estabelecido entre os componentes plurais de uma equipe de trabalho. 0 aspecto comunicacional necessário no modelo clássico do BSC converge com o multiculturalismo. A construção participativa e a comunicação da estratégia ocorrem como atos de uma instituição democrática, o que permite rechaçar o pensamento hegemônico em favor de uma proposta mais adequada para a instituição. Democrática, também, pelo fato de que todos são alvo de medição e registro, sendo que a comunicação deve funcionar multilateralmente. 
Canen e Canen (2004, p. 40) comentam que a literatura de gestão organizacional poderia ser dividida em dois grupos de artigos, considerando-se a menção que fazem aos temas "competências" e "multiculturalismo". Um grupo menciona especificamente "competências", mantendo foco sobre competências básicas, percebidas como centrais para o sucesso gerencial, dando menor atenção aos problemas multiculturais. Outro grupo de artigos multiculturalmente orientados tem sido encontrado, com tendência a dar pouca atenção a essas competências básicas necessárias para o desempenho gerencial, mas estes artigos destacam a importância em lançar estímulos para o desempenho baseado em valores como o respeito à diversidade cultural e o desafio aos estereótipos, ao racismo e ao etnocentrismo. Os autores observam que o primeiro grupo de artigos, com expressivo acervo sobre competência gerencial, está diretamente ligado à importância da geração de um clima de confiança institucional e argumentam pela necessidade de articular ambos os grupos e perspectivas para o sucesso gerencial - argumento com o qual coadunamos.

\section{Relevância da pesquisa}

A relevância da temática aqui discutida é percebida quando se realizam consultas às bases de dados Web of Science, Emerald e Scopus, disponiveis no Portal da Coordenação de Aperfeiçoamento de Pessoal de Nivel Superior (Capes), com a utilização das palavraschave desta pesquisa. É constatada nesta busca a aparente ausência de trabalhos com a palavra-chave "Balanced Scorecard", em concomitância com as relacionadas ao multiculturalismo. Consulta às teses e dissertações, tanto do Portal Capes, como da Biblioteca Digital Brasileira de Teses e Dissertações do Instituto Brasileiro de Informação em Ciência e Tecnologia (BDTD/IBICT), chegou a resultados semelhantes. 0 quantitativo levantado nesta pesquisa entre artigos, dissertações e teses leva-nos a considerar como pioneiro o presente trabalho, com a proposta da união dos temas para constituir uma gestão estratégica multicultural baseada no BSC. De fato, ao entrar com as palavras chave "Educação" e "Balanced Scorecard" em ambos os sites supra-citados, apenas 15 dissertações foram vistas no Portal Capes, sendo que nenhuma referente ao Ensino Básico.

A gestão estratégica é um tema de interesse na Engenharia de Produção, inclusive pela metodologia especifica do Balanced Scorecard. Porém, a influência do multiculturalismo na gestão, como foi visto anteriormente, não parece ser o foco dos estudos neste campo. Também, observa-se que autores como Semprini $(1999$, p. 96) destacam que os principais centros de elaboração das teses multiculturais não são os departamentos de Ciências Sociais ou Filosofia, mas os de Literatura e Estudos Étnicos, o que leva à relevância de se promover produção científica em Engenharia de Produção, tratando-se da gestão estratégica em uma abordagem multicultural.

\section{Referencial teórico}

A presente pesquisa relaciona a gestão estratégica, que se baseia no Balanced Scorecard com o multiculturalismo. Um aspecto proeminente, por parte do BSC, 
deve-se ao tratamento de ativos intangiveis e sua capacidade de buscar um foco na estratégia desenvolvida, permitindo formas diferentes para as operações em função de peculiaridades locais ou individuais, sem ameaçar o melhor desempenho do estabelecimento de ensino. Um aspecto proeminente quanto ao multiculturalismo devese à importância de dar melhor aceitação às diferenças entre seus atores, em suas múltiplas formas. Moita Lopes $(2008$, p. 136) se refere à ótica multicultural como aquela que considera os membros de uma sociedade como seres do discurso, portanto, impregnados de significados diversificados.

\section{Multiculturalismo}

Canen e Canen (1999, p. 4) explicam que a expressão "perspectiva multicultural" foi usada no campo da educação como fundamento a respeito da necessidade de sensibilizar professores quanto à pluralidade cultural e como conteúdos e práticas curriculares estariam adequados a uma proposta que não fosse etnocêntrica. Conforme Silva (2009, p. 192), discute-se, assim, no campo da Teoria do Currículo, como encontrar a melhor forma de "produzir" sujeitos particulares, como força preponderante para validar estratégias de governo e regulação, apoiando-se as posições de poder. Entretanto, a visão multicultural problematiza tais posições, visando a valorizar sujeitos excluídos e vozes plurais.

0 multiculturalismo interativo ou interculturalidade, conforme Candau (2008, p. 22), destaca-se por estimular o relacionamento entre grupos culturais, rejeitando-se os processos radicais de afirmação de identidade cultural ou os que menosprezam a diversidade cultural. A busca pelo diálogo entre diferentes grupos sociais e culturais que a autora defende pode ser realizada por uma educação para a negociação cultural.

Stühler e Assis (2009, p. 105) afirmam que, apesar do reconhecimento da diversidade, falta ainda assegurar a existência de valores como cooperação, solidariedade e pacifismo. As autoras colocam a confiança como componente necessário para o desenvolvimento de relações interpessoais construtivas, assim realçam a importância do ato de ouvir: "Quando alguém é ouvido (e compreendido), isso traz uma mudança na percepção de si mesmo, por sentir-se valorizado e aceito. E, por sentirse valorizado e aceito, pode se apresentar ao outro sem medo, sem constrangimentos." (STÜHLER; ASSIS, 2009, p. 119).

A abordagem multicultural crítica, de acordo com Canen e Canen (2005, p. 32), define-se como um conjunto de respostas à diversidade cultural, nas múltiplas áreas do conhecimento, e diante desta diversidade, busca-se entender suas fontes para administrá-las, rejeitando-se estereótipos culturais, pela manutenção de um "questionamento às relações desiguais de poder, promovendo a apreciação à diversidade cultural e desafiando preconceitos e discriminações". 
Emprega-se o conceito de "relevância do humano" (FRAGA, 2003, p. 24) em que a "compreensão" é destacada como saber rigoroso que promove a superação de preconceitos e estabelece a comunicação multilateral. Com o critério da "relevância do humano", busca-se a valorização da consequência, não do simples resultado. Segue-se com a abordagem do movimento da desconstrução introduzido por Derrida (2007) para uma análise e ação diante da pluralidade cultural e em relação ao pensamento hegemônico. Destaca-se o ato da compreensão como consequência possivel quando a diferença e heterogeneidade das recepções e enunciados são respeitadas.

Fisher, Ury e Patton $(2005$, p. 59) trazem contribuição sobre conflitos e conciliação de interesses. Eles diferenciam a "conciliação de interesses" em relação à "conciliação de posições", conceitos relacionados a conflito e negociação. Para Likert e Likert (1979, p. 146), quando uma instituição tem a compreensão da diversidade como algo de valor, surge a necessidade de dar atenção e prestar apoio ao seu interlocutor, demonstrando interesse e consideração para ouvir o outro, independente de existir concordância.

Segundo Canen e Canen (1999, p. 7), busca-se organizar conhecimentos que propiciem o alto desempenho dos gestores em ambientes culturalmente dispares. Por meio de uma capacitação gerencial nesta abordagem multicultural, pode-se chegar à superação dos limites de visões etnocêntricas, estimulando-se o desenvolvimento de valores como o apreço à diversidade cultural e a clara compreensão que nenhum valor cultural é superior por si mesmo. Destaca-se a importância de estudos comparativos em relação às culturas locais, a fim de se delinear as características especificas de política e identidade cultural e suas respectivas respostas gerenciais nos diversos âmbitos institucionais, para solucionar ou evitar conflitos.

Trompenaars (1994, p. 25) concluiu que há variações entre culturas e também inúmeras semelhanças dentro de cada uma, possibilitando uma previsibilidade de comportamento, como representado por uma distribuição normal. Observou, ainda, que as culturas variam em função das soluções dadas a problemas comuns, e que as organizações não reagem apenas a seu ambiente. Elas selecionam, interpretam, escolhem e criam ativamente seus ambientes.

Destaca-se o conceito de "estereotipagem" como uso de formas extremas e exageradas a partir da observação do comportamento do outro e entendimento do diferente como errado. Neste sentido, desconsidera-se que a personalidade individual se interpõe a cada sistema cultural e que indivíduos da mesma cultura não se comportam necessariamente de acordo com a norma cultural (TROMPENAARS, 1994, p. 27).

No sentido da comunicabilidade, apresenta-se como desafio do multiculturalismo a busca de caminhos de mediação e de tradução entre estes grupos. 0 dinamismo das reivindicações identitárias, tanto no conteúdo como na forma de expressão, depende 
das modalidades de articulação do grupo minoritário no espaço social maior. 0 processo de marginalização de um conjunto de indivíduos favorece a criação e coesão dos grupos, encadeando-se no desejo de conquistar uma visibilidade externa e chegar a ser percebido como minoria pelo espaço social circundante (SEMPRINI, 1999, p. 59).

Porém a efetivação do êxito institucional, com a percepção por parte das pessoas sobre a valorização de suas identidades culturais, dependeria da garantia da formação de um ambiente baseado na confiança. Figueiredo $(2007$, p. 39) cita elementos organizacionais que favorecem o desenvolvimento das parcerias e destaca a necessidade de que estes elementos sejam constituidos e mantidos a longo prazo. Dentre eles, podemos destacar, para esta pesquisa, a compatibilidade cultural e o desejo de parceria. A manutenção desta parceria se apoia na confiança como componente essencial.

Derrida (2007), que introduziu o conceito de desconstrução, considerava o direito como elemento do cálculo, mas a justiça como o incalculável, visto que há momentos em que a decisão entre o justo e o injusto não é garantida por uma regra. A desconstrução busca atender à exigência de justiça infinita, pelo conhecimento de nosso aparelho conceitual, teórico ou normativo em torno da justiça. Reconhece que as injustiças ocorrem pela manutenção de dogmas que impedem a livre reflexão. Porém, quando ocorre a livre reflexão, propiciam-se transformações mais fundamentais, inclusive, jurídico-políticas (DERRIDA, 2007, p. 38-39).

Conforme Vergara (2006, p. 63), o ato de desconstruir começa por revelar as ideias presentes no texto tanto de forma mais imediata ou mais encoberta, e repensar cada significado exposto, seja presente no texto ou ligado a este. 0 movimento da desconstrução é especialmente de compreensão, e esta compreensão é o ato apresentado por Semprini (1999, p. 73-74) como consequência possível quando a diferença e heterogeneidade das recepções e enunciados são respeitadas.

Convergindo com este movimento da desconstrução, Fraga (2003, p. 33) apresenta o conceito de transformação intersubjetiva, quando se abre caminho para libertar o outro da posição de objeto de dominação. Isto realça a importância de desenvolver competências para negociação, tendo como princípio valorizar a sensibilidade multicultural para que se possa estar diante de tensões naturais da interação. Neste sentido, pode-se citar Trompenaars (1994, p. 22), que explica a cultura representada em níveis, sendo um externo com produtos explícitos, um intermediário com normas e valores, e um núcleo central com premissas sobre a existência, e correspondem aos seguintes significados, respectivamente. No nível externo, a cultura explícita é a realidade observável da língua, culinária, arquitetura, monumentos, agricultura, templos, mercados, vestimentas e arte. No nível intermediário, as normas se apresentam como o sentimento mútuo que um grupo considera certo ou errado, e concretizam-se em controle social ou leis aprovadas. Já os valores 
estão intimamente relacionados aos ideais compartilhados por um grupo. Uma cultura é relativamente estável quando as normas refletem os valores do grupo. Quando isso não acontece, provavelmente há uma tensão desestabilizadora.

No núcleo central, o valor mais básico que mobiliza as pessoas é a sobrevivência, o que se apresenta em diversas civilizações, em enfrentar a natureza, dando respostas rotineiras ao ambiente. Trompenaars (1994, p. 12-13) adverte sobre as consequências prejudiciais de se limitar a complexidade da administração, por meio de ferramentas gerenciais, com a tendência a restringir a inovação e o sucesso intercultural. Define a cultura como "propriamente um produto cultural" e destaca que "cultura é um sistema comum de significados, que nos mostra a que devemos prestar atenção, como devemos agir e o que devemos valorizar" e que no meio institucional, a "cultura permeia e irradia significados em todos os aspectos da empresa. A cultura molda todo o campo dos relacionamentos empresariais".

Hofstede (1997, p. 28-29), em 1965, teve a oportunidade de estudar um grande conjunto de dados sobre os valores de cidadãos de mais de 50 paises, repartidos em cinco continentes. Eram pessoas de filiais da IBM, em postos de trabalho idênticos, em paises diferentes, que responderam a questões relativas aos seus valores. A análise estatística das respostas revelou a existência de problemas comuns, mas de soluções diferentes conforme o pais, nos seguintes aspectos: desigualdade social, que inclui relação com a autoridade; relação indivíduo-grupo; conceitos de masculinidade/feminilidade; forma de gerir a incerteza - inclui agressividade e expressão de emoções.

Dentre suas afirmações, Hofstede $(1997$, p. 18) faz referência a uma programação, delimitada às reações mais prováveis e compreensiveis em função do passado de cada um. Esta programação tem relação com padrões de pensamentos, sentimentos e comportamentos de cada um, que, antes de aprender algo diferente, torna-se necessário desaprender, e desaprender apresenta-se como tarefa mais difícil do que aprender pela primeira vez.

Estas diferenças mais essencialmente verificam-se nos valores, que o autor distingue em áreas de atuação como "relação com o poder e a desigualdade", "relação entre o indivíduo e o grupo", relação com os "papéis sociais do homem e mulher", "formas de lidar com as incertezas da vida", e o grau de atenção "face ao futuro ou ao presente e passado". Os valores têm ainda um papel principal no sucesso do convívio intercultural, o que defende Hofstede (1997, p. 273), resguardando a importância da identidade. Esta que dá o sentimento de segurança, permitindo a aproximação com outras culturas, e possibilitando conviver e cooperar apesar das diferenças existentes no modo de pensar, sentir ou agir. Pamplona $(2009$, p. 61) ressalta que a escola desconsidera as diferenças socioculturais que encontra em seu ambiente e acaba por privilegiar manifestações e valores culturais das classes dominantes, e isto conduz ao favorecimento de uns em detrimento de outros. 
A advertência sobre o campo institucional, que coloca o gestor em situação tanto de influenciador como de influenciado pelos membros das equipes de trabaIho, conforme os aspectos culturais de cada um leva a uma reflexão no sentido de reconhecer que, apesar da liberdade dos gestores, estes estão restritos aos "condicionantes culturais" mais do que as publicações sobre gestão admitem, como sugere Hofstede (1997, p. 275), considerando este ambiente de convivio profissional um "laboratório adequado para a cooperação intercultural" com a superação da tendência a "dar prioridade aos pontos de vista de interesse estritamente econômico".

\section{Reflexões sobre o BSC}

A estrutura original do BSC é formada por quatro perspectivas denominadas respectivamente de "perspectiva financeira", "perspectiva do cliente", "perspectiva dos processos internos" e "perspectiva de aprendizado e inovação". Cada perspectiva funciona como um receptáculo que abarca, por afinidade, um conjunto de objetivos, indicadores de desempenho, metas e iniciativas de melhorias para o alcance destas metas. Todas estas informações, e ainda o relacionamento entre os indicadores de desempenho, são representados em um documento denominado de mapa estratégico.

A relação entre indicadores de desempenho mostra que uma melhoria em um indicador pode gerar melhoria em um ou mais indicadores, de uma mesma ou de diferentes perspectivas. Esta relação entre indicadores de desempenho, denominada "relação causa e efeito", geralmente é definida no momento do planejamento e construção do modelo BSC próprio da instituição a que se destina. Destaca-se, assim, a necessidade de aprimorar o modo de representação das perspectivas no mapa estratégico, buscando-se superar as relações lineares de causa e efeito, por exemplo, do tipo "do topo para baixo" estabelecendo uma relação matricial mais adequada à prática de gestão e considera-se o que Kaplan e Norton (2004a, p. 107) afirmam ser a melhor maneira de construir mapas estratégicos, ou seja, de cima para baixo.

Corrêa (2005, p. 122) discorre sobre a necessidade de reformulações no modelo padrão do BSC, para que possa viabilizar no sentido mais amplo, o alcance de seus propósitos. A autora faz relação à Teoria da Complexidade, apontando o ambiente organizacional como um sistema complexo, resultando, assim, no estabelecimento impreciso das relações de causa e efeito.

Revelam-se, dai, aspectos para a reflexão sobre o BSC. Por exemplo, um primeiro caso é o caso de melhoria ou queda de um indicador que impactaria em outro cuja relação não tenha sido prevista no modelo BSC. Mesmo em um segundo caso, se a melhoria ou queda de um indicador estiver representada no modelo, caberia expressar o quanto seria o fator ou função de seu impacto. Terceiro, o grau de mudança em um indicador poderia gerar impacto em outros de forma não linear. Quarto, considerando- 
se que a relação de causa e efeito expressa que a mudança em um indicador "A" gera impacto em um indicador "B", tal constatação não explicita em que medida o indicador "B" estaria em mudança por outras causas. Quinto, espera-se que a variação do indicador "A" resulte na variação do indicador "B", porém, poderia ocorrer que a variação de "B" impactasse na variação de "A". 0 tratamento destes casos serve para direcionar a modelagem do BSC para uma abordagem sistêmica, envolvendo, dentre outros aspectos, a relação entre os indicadores de desempenho. A relação entre causa e efeito pode ser resultante de uma análise apoiada pela exploração computacional sobre o histórico de desempenho, possibilitando-se superar limitações analiticas do BSC.

De forma conciliatória, Corrêa (2005, p. 235-236) defende que a proposta dos autores do BSC quanto às relações de causa e efeito traz a possibilidade de tratar a organização de forma "sistêmica e dinâmica", abrindo-se caminho para a definição de "hipóteses probabilisticas da estratégia", que serão confirmadas ou rejeitadas ao longo do processo de gestão. Dentre as caracteristicas necessárias e desejáveis enumeradas de um software BSC, conforme Niven (2007, p. 314), destaca-se a capacidade de análise estatística multidimensional de desempenho, apontando-se tendências. 0 software teria um mecanismo para rastreamento e análise do desempenho organizacional instantaneamente, considerandose as relações de causa-efeito definidas no mapa estratégico. Tendências e causas poderiam ser levantadas com o uso desta ferramenta de apoio à análise. A ferramenta permite gerenciar o desempenho, possibilitando-se o alinhamento de pessoas, processos e tecnologias sobre planos comuns, para executar e otimizar estratégias organizacionais.

Porém, converge com os cuidados iniciais quanto ao sucesso das ferramentas de gestão, não menos com o BSC, o que Corrêa $(2005$, p. 309) ressalta sobre a necessidade do comprometimento dos dirigentes. A autora adverte sobre o caso de insucesso na implementação do programa de gestão quando não havia comprometimento dos dirigentes. Ao contrário, casos de sucesso foram encontrados nos estabelecimentos em que foram constatados comprometimento de seus líderes. Tal aspecto é perpassado pela visão multicultural. De fato, segundo Canen e Canen (2008), a liderança multicultural de gestores é central para o sucesso organizacional, fomentando a valorização das diferenças e a construção de um ambiente positivo, comprometido com o sucesso.

Numa abordagem sistêmica, busca-se definir iniciativas de melhoria para todas as metas do plano estratégico. Durante a execução da estratégia, todas as iniciativas de melhoria devem ser consideradas o mais amplamente possivel, envolvendo os diversos grupos de profissionais e os diversos grupos de alunos, para os quais a visão multicultural anteriormente abordada pode contribuir.

Esta execução dependerá também de recursos e trará a necessidade de priorizações. Priorizar servirá para garantir o sucesso de um conjunto de iniciativas de melhoria. 0 processo de priorização deverá ser participativo, democrático e multicultural. 
Quando não ocorre um crescimento esperado em uma medida de desempenho, há o risco de uma queda da credibilidade que os profissionais têm da gestão ou de seus gestores, e consequentemente, um desbalanceamento das demais medidas de desempenho, configurando-se em uma situação de perda de governança. Este poderá ser mais um motivo de questionamento da relação linear de causa e efeito, já que fatores além de recursos e competências podem entrar como peças fundamentais no alcance das metas, fatores estes resultantes, em grande parte das vezes, de relações monoculturais, que ignoram a pluralidade na organização.

A escassez de recursos para determinada iniciativa nem sempre será justificativa para seu adiamento. Esta iniciativa poderá se desdobrar em mais ações, incluindo a busca destes recursos. Deve-se considerar, também, que os privilégios, incluídos nesta análise, geram insatisfação, por serem estes considerados atos baseados em critérios

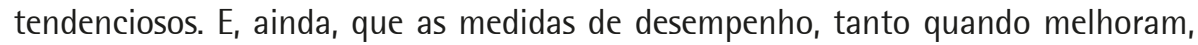
estacionam ou pioram, devem ser publicadas e também percebidas nas observações sobre o contexto avaliado - o que garante maior transparência e equidade.

Por outro lado, quando ocorre uma melhoria esperada em uma medida de desempenho, esta serve como impulsionador da credibilidade que os profissionais têm da gestão ou de seus gestores, uma possibilidade de coesão e ambiente mais propício ao desenvolvimento da confiança e do sentimento de pertença, podendo trazer, como consequência, 0 aumento da pró-atividade. $A$ ação das equipes pode melhorar outros pontos importantes da instituição que, até então, poderiam não ter sido planejados.

Interessa, neste sistema de gestão participativa, conhecer o trajeto de cada participante, como percebe a instituição e como atua nela. A sensação de progresso, considerando-se tanto as medidas de desempenho como a percepção dos participantes desta instituição, não deveria gerar um decréscimo nos compromissos ora traduzidos em metas. 0 questionamento das relações lineares de causa e efeito também ocorre no caso dos deslocamentos favoráveis das medidas de desempenho, podendo atingir indicadores que não estavam imediatamente interligados no mapa estratégico.

A relação de causa e efeito é uma informação que pode ser fornecida para confecção e atualização do mapa estratégico, e pode ser influenciada pelas culturas dos membros da instituição, o que configura a dimensão multicultural do processo. Esta informação também pode ser resultante de algoritmos que indiquem a correlação entre medidas de desempenho, possibilitando-se a descoberta de outras relações de causa e efeito, inspirando-se a definição de novas iniciativas de melhoria.

Carvalho (2009, p. 27), ao se referir à implementação do BSC, enfatiza a necessidade de se tratar de "eventuais resistências culturais". Apesar de uma advertência sobre a necessidade de se ter adequada relação com os outros sistemas gerenciais existentes na 
organização, no entanto, parece divergir das premissas centrais do multiculturalismo, uma vez que o que está sendo chamado de "resistências", é uma tendência que parece inferiorizar as características culturais de grupos ou pessoas com identidades culturais diferentes da cultura hegemônica. Trompenaars $(1994$, p. 6), por outro lado, afirma que a cultura não mantém situação favorável para os métodos oferecidos como solução universal e que não estejam de acordo com as necessidades locais - enfatizando a importância das culturas plurais. Servem, como exemplo, as soluções denominadas "meIhores práticas", que buscam garantir primordialmente a eficiência econômica.

O BSC, como ferramenta para descrever e determinar o valor gerado pelos ativos intangiveis - no caso, multiculturais - mostra importante caracteristica desta metodologia que, conforme Kaplan e Norton (2004a, p. 101), supera os sistemas de gestão tradicionais. A avaliação dos ativos intangiveis pode abranger aspectos culturais, como defendido no presente artigo, considerando-se forte relação do contexto institucional e da estratégia em que se baseia. O BSC tem como elemento central, a estratégia e a visão, não o controle. As metas são estabelecidas, mas os comportamentos e ações para alcançar estas metas não são fixos. Os indicadores funcionam como elemento de visibilidade para todos da instituição. Espera-se alcançar as metas, com a possibilidade de ajustar as ações conforme as necessidades ambientais. Os choques culturais, elementos intangiveis do sistema de gestão, aparecem como problemas no BSC, e podem ser relacionados: à sua implementação, às ações de esclarecimento e compartilhamento e à gerência da estratégia, com o apoio da sensibilização multicultural.

A alocação de recursos e definição de prioridades, em uma instituição que tem sua gestão baseada no multiculturalismo, passa a ser realizada participativamente, o que inclui a avaliação das atividades que propiciam o alcance de objetivos estratégicos de longo prazo, fazendo com que este processo resulte em orçamentos estratégicos.

Automatizar o Balanced Scorecard propicia a otimização de seu uso como um sistema de medição, um sistema de gerenciamento estratégico e uma ferramenta de comunicação. Possibilita acompanhar as metas e o respectivo desempenho por indivíduo, equipe ou instituição; portanto, converge com a diretriz de construção conjunta da informação e seu amplo compartilhamento, transparentemente, que exigirá de seus gestores a condução necessária para manutenção de um ambiente de confiança mútua, condensado com a visão da liderança multicultural (CANEN; CANEN, 2008).

Esta confiança propiciará, de forma produtiva, o fluxo da informação e as respectivas avaliações, o que inclui a confirmação da validade da teoria subjacente à estratégia departamental e institucional, conforme Kaplan e Norton (2004a, p. 93), que já destacaram a importância da comprovação destas correlações. Mesmo tendo que conviver com a demora na obtenção de dados, e sabendo-se que parte destes dados são qualitativos e subjetivos, deve-se cuidar para que as decisões não sejam tomadas com base em resultados operacionais de curto prazo. Dai a importância de ter, como referência, esta teoria subjacente. 


\section{Proposta de Gestão Estratégica Multicultural (GEM)}

A proposta de Gestão Estratégica Multicultural (GEM) faz uma ligação entre o BSC e a teoria básica do multiculturalismo. A proposta GEM corrobora com a estrutura do BSC proposta por Kaplan e Norton (1997, 2004a, 2004b), que possibilita acompanhar o desempenho institucional através de indicadores e promove a alavancagem destes indicadores por meio de processos participativos. A arquitetura geral desta proposta é apresentada na Figura 1. Foi estruturada para propiciar a implementação da Gestão Estratégica Multicultural, resultando em melhor desempenho institucional, e fundamenta-se no desenvolvimento de uma gestão baseada no conhecimento e confiança que supere conflitos, incertezas e imprevisibilidade, com o entendimento das fontes da diversidade cultural e a administração deste contexto.

Figura 1: Diagrama da Proposta de Gestão Estratégica Multicultural (GEM).

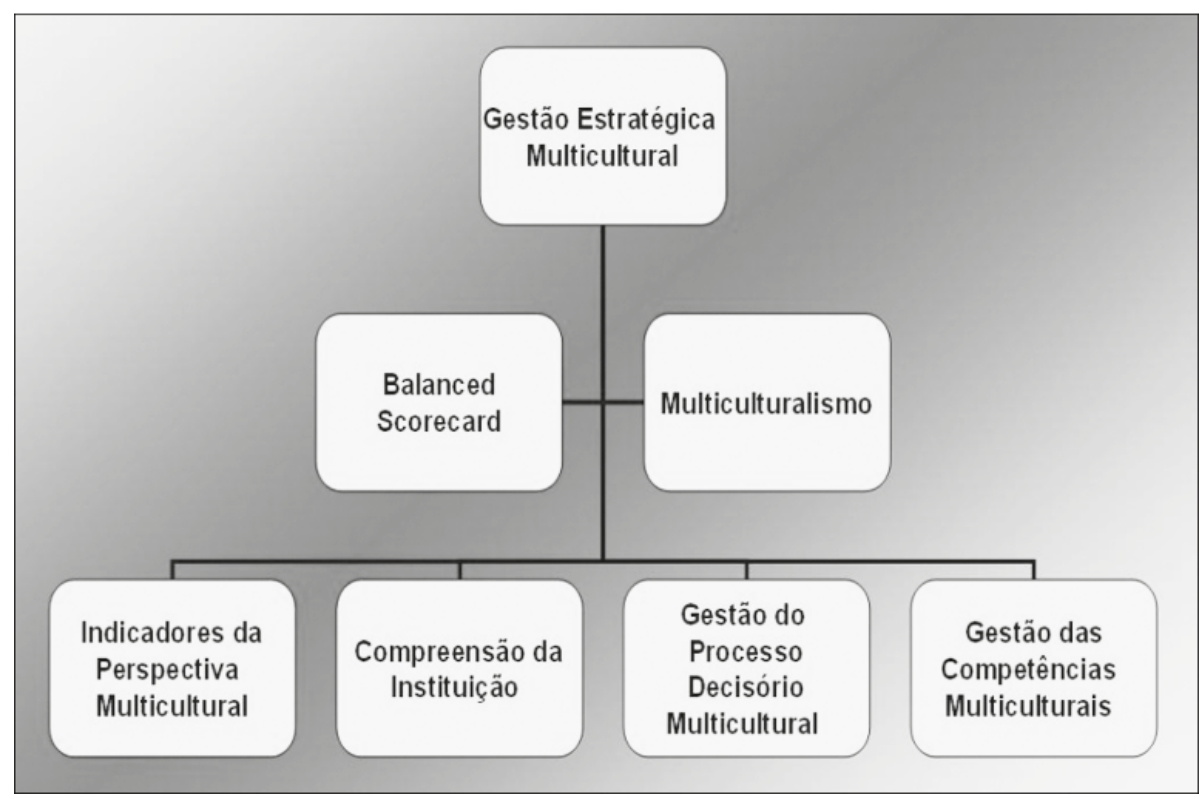

Fonte: Kaplan e Norton (2004a, 2004b).

Nesta proposta, busca-se permanentemente manter o trabalho de pesquisa e alavancá-lo com a participação dos diferentes atores da instituição, convergindo para a gestão do conhecimento e a valorização da intersubjetividade, da multiculturalidade, sem excluir o profissional pesquisador.

Uma complexa rede de interações comunicativas desencadeia processos de formação que agem no estabelecimento das subjetividades dos indivíduos plurais. Nes- 
tas interações, seus atores buscam validade de suas manifestações atendendo a requisitos como o de ser o enunciado verdadeiro, o de que suas manifestações devem estar de acordo com um sistema normativo legítimo, e que haja coincidência entre expressão e intenção (GONÇALVES, 1999, p. 136).

0 pesquisador, com as ferramentas de auxílio ao seu trabalho, aqui propostas, fica mais livre para a orientação das pesquisas, favorecendo a descoberta de mais elos na fase de análise, evitando-se que passem despercebidas as especificidades e singularidades culturais dos sujeitos.

Continuamente, registros com os respectivos elos são produzidos e disponibilizados para todos os colaboradores da instituição. E as ferramentas propostas serviriam também como instrumentos de registro e apuração de processos de sufrágio e acompanhamento no que diz respeito à compatibilidade entre escolhas e ações de seus agentes no processo decisório. Permitiriam registrar os critérios que são definidos em consenso, suas possíveis consequências a priori, bem como favorecem o acompanhamento das ações escolhidas ou da omissão, viabilizando a manutenção de registros históricos. 0 registro de contexto inclui sujeitos plurais e respectivos papéis, fatos e problemáticas, conflitos, surpresas, novas previsões, sinais de alarme, etc. Com este sistema de informação constituido, torna-se viável a construção de indicadores de desempenho em cada perspectiva do BSC, possibilitando acompanhar as iniciativas de melhoria para realizar a missão, a visão e os objetivos institucionais, em uma visão de valorização da diversidade cultural.

\section{Procedimentos e recomendações metodológicas para melhoria do desempenho}

A proposta de Gestão Estratégica Multicultural (GEM) é organizada em conjuntos de procedimentos e recomendações metodológicas para a melhoria do desempenho institucional, bem como um sistema de medidas. Reúne as características do BSC com funcionalidades que apoiam a gestão multicultural.

0 conjunto "Compreensão da Instituição" tem o objetivo de manter os dados e análises organizados de forma a obter maior compreensão da instituição, resultando, em conclusões-chave para a gestão. Seus procedimentos e recomendações metodológicas correspondem à proposta de organização de registros e métodos para a renovação contínua dos ciclos de gestão, que passam por investigação e decisão.

O conjunto "Gestão do Processo Decisório Multicultural" toma como base as recomendações de Fisher, Ury e Patton (2005, p. 69) quanto à importância para o processo decisório. Necessita-se elaborar uma descrição do problema e apresentála antes da proposta de solução, com o cuidado de reconhecer os interesses da 
outra parte da discussão como elemento do problema global. Após conhecer os interesses e razões, propostas de solução são apresentadas. Os critérios e motivos usados por cada lado da discussão não são automaticamente conhecidos por todos, nem imediatamente interpretados, o que faz necessário ter um tratamento metódico, multiculturalmente sensivel, para esclarecê-los.

Diversas posturas servem para enfrentar construtivamente a diversidade. Fisher, Ury e Patton $(2005$, p. 93) defendem uma melhor aproximação entre as partes, 0 que pode ser feito com o apoio de um árbitro imparcial e procedimentos para tratar de situações de divergência. As preocupações futuras tornam-se prioridade e as queixas anteriores passam pela exigência de serem superadas. $E$, ainda, deve-se focar nas possibilidades de benefícios mútuos, para favorecer o desenvolvimento de uma relação vantajosa para todos os envolvidos, com a satisfação dos interesses das partes culturalmente diversas, com soluções criativas.

0 conjunto "Gestão das Competências Multiculturais" tem o objetivo de colaborar com o desenvolvimento da sensibilidade quanto à pluralidade cultural, apoiar a mediação e a tradução entre os grupos, com atenção ao reconhecimento das peculiaridades de cada um. 0 desenvolvimento de competências relacionais faz-se necessário por considerar-se que, num contexto de forte mobilidade social, há escassez destas competências para tratar de seus conflitos próprios. A incapacidade dos indivíduos de resolverem suas diferenças com outras formas de recursos que não os conflitos conduzem à frustração nas práticas de negociação (SEMPRINI, 1999, p. 78).

0 próprio modo de tratar o ser humano torna-se preocupação fundamental nesta proposta de gestão. Neste sentido, deve-se reprovar o que Semprini (1999, p. 105) chama de depreciação sistemática, que afeta pesadamente a autoestima de um indivíduo e acaba sendo interiorizada e instalada no âmago de sua identidade, contrariamente à perspectiva multicultural aqui defendida.

\section{Sistema de medidas de desempenho ampliando o BSC}

Adaptações na modelagem do BSC para atender às peculiaridades de instituições de ensino são prescritas na proposta GEM e apresentadas no Quadro 1. Desta forma, as perspectivas da estrutura original do BSC podem ser mantidas, ressignificadas ou renomeadas. Propomos que sejam mantidas as Perspectivas "dos processos internos" e a "financeira". A "Perspectiva do Cliente", para o caso de sistemas de ensino deve ser substituida pela "Perspectiva de desenvolvimento do Corpo Discente". A "Perspectiva de Aprendizado e Inovação" ou "Perspectiva de Aprendizado e Crescimento" passa a ser intitulada de "Perspectiva de Inovação Institucional ou de Inovação Escolar", todas estas dimensões perpassadas pela perspectiva multicultural. 
Quadro 1: Perspectivas do BSC adaptadas a instituições de ensino na abordagem multicultural.

\begin{tabular}{|c|c|}
\hline Perspectivas do Modelo Original & Perspectivas do Modelo Proposto \\
\hline Financeira & Financeira \\
\hline do Cliente & de Desenvolvimento do Corpo Discente \\
\hline Processos Internos & Processos Internos \\
\hline Aprendizado e Inovação & de Inovação Institucional \\
\hline-- & Multicultural \\
\hline
\end{tabular}

Fonte: Os autores (2011).

Diversas funcionalidades do BSC são mantidas neste contexto, como a construção de indicadores chave de desempenho, mapas estratégicos, árvore de métricas e incluindo o uso de alertas, medidas de convergência e de dispersão, que indicam o grau de alcance das metas.

Assim, é proposto neste trabalho, uma nova perspectiva do BSC, à luz do multiculturalismo com cinco indicadores de desempenho: indicador de "Pesquisa para compreensão"; indicador de "Negociação"; indicador de "Autonomia/autoestima"; indicador de "Solidariedade" e indicador de "Liderança".

Um indicador é formado por um conjunto de medidas para um determinado período, definido participativamente. Desta forma, seria possivel comparar o crescimento de um indicador ou de suas medidas ao longo do tempo. Seria possivel acompanhar o comportamento das medidas ou indicadores, com a finalidade de conhecer dependências.

Os dados referentes às medidas são obtidos pela observação realizada por um conjunto de pessoas designadas para tal. Daí, uma medida poderia ter um valor diferente para cada observador. Neste caso, um método para condensar as diferentes observações poderia ser aplicado, inclusive com a atribuição prévia de peso para cada observador. A atribuição de peso para cada observador sobre uma medida específica depende de grau de experiência deste observador, especificamente sobre o assunto da medida. Além da experiência, outros atributos são considerados, como, por exemplo, a imparcialidade do observador.

De uma forma mais simplificada, a atribuição de peso para cada observador poderia ser independente da medida $\mathrm{j}$, considerando-se, assim, um grau de experiência geral. Uma situação intermediária pode ser estabelecida, atribuindose peso para cada observador, para cada indicador de desempenho da perspectiva multicultural, considerando-se, assim, um grau de experiência relativo a cada indicador desta perspectiva. 
Corroborando com a escala que indica o grau de percepção de determinado elemento, cabe registrar, para cada observador concorrente, sua descrição ou justificativa de sua pontuação, servindo estes dados qualitativos para futura validação junto aos dados sobre a escala, dados estes que representam suas perspectivas plurais, centrais para o olhar multicultural.

\section{Resumo de Medidas de Desempenho}

As seguintes medidas foram criadas a partir da reflexão propiciada pela pesquisa bibliográfica e pela observação problematizada de contextos institucionais por nós analisados para testar e construir o modelo proposto. 0 Quadro 2 apresenta uma proposta de estrutura de medidas para composição do indicador de "Liderança". Considera-se "liderança" no sentido da atuação inspiradora ou motivacional (FRAGA, 2003, p. 46), e numa perspectiva multicultural (CANEN; CANEN, 2008) compreendem o líder como favorecedor do respeito mútuo e da redução das discriminações e preconceitos. As lideranças da instituição devem conduzir o processo de acompanhamento e estímulo à participação de todos, garantindo a ética e desafiando situações criadas por polarizações de modo a minimizar conflitos (CANEN; CANEN, 2008).

Quadro 2: Algumas medidas que compõem o indicador de "Liderança".

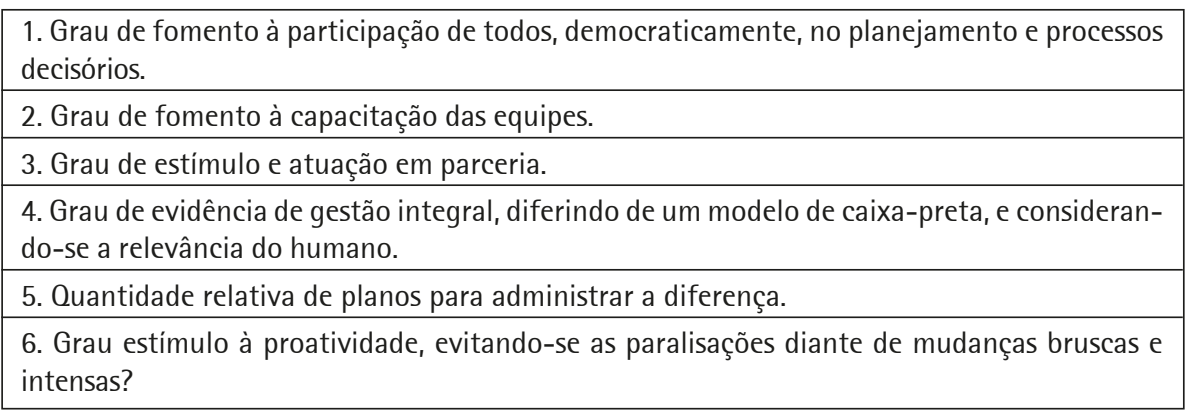

Fonte: Os autores (2011).

0 Quadro 3 apresenta uma proposta de estrutura de medidas para a composição do indicador de "Negociação". Almeja-se criar as condições para o ingresso de outros participantes no processo decisório, em um relacionamento baseado na tolerância e na valorização da diversidade cultural (CANEN; CANEN, 2005; CANEN; CANEN, 2008), na qual se possa potencializar a comunicação construtiva, propiciando conversação pelo estabelecimento da paz, do diálogo, da negociação. Busca-se, com este indicador, acompanhar o crescimento da capacidade de cada um na solução de situações que surjam em função de suas diferenças. 
Considera-se importante, nesta medição, o grau de aceitação da pressão argumentativa e seu empenho em preparar seus integrantes para ouvirem e interpretarem, como movimentos imprescindíveis do processo de compreensão. 0 que o outro fala, passa a ser considerado importante, não apenas por relacionar-se diretamente com a execução de uma tarefa ou de uma negociação, mas como contribuição num processo coletivo e multicultural de construção.

Quadro 3: Algumas medidas que compõem o indicador de "Negociação".

\begin{tabular}{|l|}
\hline 1. Grau de estímulo para busca de soluções de conflitos. \\
\hline 2. Grau de superação efetiva de conflitos. \\
\hline 3. Grau de legitimidade nas deliberações. \\
\hline 4. Grau relativo de tratamento dos casos omissos, sobre planos, regulamentos, normas, Leis, etc. \\
\hline 5. Grau relativo de debate para apreensão das restrições reais e possíveis do contexto. \\
\hline $\begin{array}{l}\text { 6. Grau de estímulo à preocupação mútua, superando-se a preocupação exclusiva com seus } \\
\text { próprios interesses imediatos. }\end{array}$ \\
\hline
\end{tabular}

Fonte: Os autores (2011).

0 Quadro 4 apresenta uma proposta de estrutura de medidas para a composição do indicador de "Solidariedade". Busca-se o desenvolvimento da solidariedade que permita estar atento ao outro com senso de humanidade, de apreciação às diferenças culturais e, ainda, ampliar a capacidade de colaborar com o pleno desenvolvimento do grupo, estando atento às possibilidades de atuação empreendedora nas quais poderá ser efetivado o amadurecimento das equipes e as inovações.

0 Quadro 4: Algumas medidas que compõem o indicador de "Solidariedade".

\begin{tabular}{|l|}
\hline 1. Grau de adequação dos julgamentos às culturas envolvidas. \\
\hline 2. Grau de tolerância mútua. \\
\hline 3. Grau de colaboração mútua. \\
\hline 4. Grau de preocupação com o outro. \\
\hline
\end{tabular}

Fonte: Os autores (2011).

0 Quadro 5 apresenta uma proposta de estrutura de medidas para a composição do indicador de "Pesquisa para compreensão". É um importante indicador para medir e acompanhar o crescimento da percepção, por parte das pessoas, sobre a valorização de suas identidades culturais que, pelo já exposto anteriormente, depende da garantia da formação de um ambiente baseado na confiança (CANEN; CANEN, 2004, p. 42). 
Quadro 5: Algumas medidas que compõem o indicador de "Pesquisa para compreensão".

1. Grau de evidência da prática de compartilhamento dos resultados das pesquisas, sejam dados, análises e seus desdobramentos.

2. Grau de evidência da prática de validação dos dados.

3. Grau de identificação de padrões de comunicação heterogênea (em vez de comunicação hegemônica).

4. Grau relativo de debate para conhecer antecipadamente as consequências.

Fonte: Os autores (2011).

0 Quadro 6 apresenta uma proposta de estrutura de medidas para a composição do indicador de "Autonomia/autoestima". Baseia-se no conceito de democracia que, segundo Fraga (2003, p. 12), é forma de representação que, ao invés de permitir e/ou conviver com a exclusão, propõe a inclusão, para a participação ampla e autêntica dos sujeitos.

Quadro 6: Algumas medidas que compõem o indicador de "Autonomia/autoestima".

\begin{tabular}{|l|}
\hline 1. Grau de manifestação de reconhecimento e sua percepção por parte do outro. \\
\hline 2. Grau de percepção de ser útil. \\
\hline 3. Grau de sentimento de estar em processo de desenvolvimento. \\
\hline 4. Grau de liberdade para ação criativa, individualmente e em equipe. \\
\hline $\begin{array}{l}\text { 5. Grau de sentimento de aceitação de cada um pelas equipes para participar na construção } \\
\text { da informação e no processo decisório. }\end{array}$ \\
\hline
\end{tabular}

Fonte: Os autores (2011).

Busca-se, ainda, possibilitar o registro de textos avaliativos complementares. Os textos avaliativos poderão passar por outras fases de processamento para alcançar conteúdos de síntese, com a devida categorização servindo para a construção dos parâmetros estratégicos.

A implementação da proposta GEM em Instituições de Ensino inicia-se pela decisão de seus gestores em manter tal processo em benefício da referida instituição. Este será o primordial apoio para que o processo seja conduzido com sucesso. 0 estabelecimento de um projeto para implementar esta proposta de gestão propiciará o apoio dos profissionais da instituição. Este projeto poderá iniciar com o estabelecimento da visão estratégica, desdobrando-se em objetivos estratégicos nas perspectivas recomendadas. Os objetivos teriam indicadores de desempenho associados e, em seguida, as metas estratégicas, com as ações de melhorias. Neste projeto, estaria incluída a perspectiva multicultural com seus objetivos, indicadores e metas estratégicas. Desta forma, a implementação da articulação do BSC e da perspectiva multicultural pode contribuir para o aprimoramento da gestão educacional, tão relevante para a melhoria constante da nossa educação. 


\section{Conclusão}

A pesquisa sobre o multiculturalismo para apoio à gestão estratégica responde ao interesse da construção de conceitos e procedimentos que convirjam com o BSC, e possibilitem a compreensão dos conflitos entre grupos provenientes de choques culturais e favoreçam o estabelecimento de competências multiculturais para superar tais conflitos. Por isto, questionam-se as visões etnocêntricas, como também a imposição de uniformidade das organizações globais e a massificação.

Os valores básicos presentes no processo de construção das competências multiculturais exigem a superação do temor das diferenças e, em contrapartida, realçam a valorização do compartilhamento, a busca de intersubjetividade e o convivio com uma multiplicidade de singularidades.

Neste trabalho, consideram-se não apenas as diferenças culturais entre grupos, mas também as diferenças entre indivíduos dentro de um mesmo grupo. Neste sentido, cabe rechaçar a prática da "estereotipagem", evitando-se julgamentos inadequados contra o indivíduo que se mostra como diferente.

A importância de tratar de conflitos e das competências multiculturais para superá-los é aí relevante para a gestão estratégica. A construção de uma estrutura para aplicação do BSC com a identificação, construção e manutenção de competências próprias do multiculturalismo, que inclui a intersubjetividade, estabelecendo-se um ambiente de confiança com valorização e reconhecimento de cada ator propiciando-se as iniciativas de negociação e tolerância foi discutida no presente artigo. Defendeu-se que sua aplicação na gestão de instituições de ensino pode contribuir para o aperfeiçoamento constante destes processos administrativos, colaborando para uma possivel maior eficiência do nosso sistema educacional - temática relevante no contexto brasileiro atual.

\section{Referências}

CANDAU, V. M. Multiculturalismo e educação: desafios para a prática pedagógica. In: MOREIRA, A. F.; CANDAU, V. M. (Org.). Multiculturalismo: diferenças culturais e práticas pedagógicas. Petrópolis: Vozes, 2008.

CANEN, A. G.; CANEN, A. Logistics and cultural diversity: hand in hand for organisational success. Cross cultural management: an international journal, United Kingdom, v. 6, n. 1, p. 3-10, 1999.

A. Multicultural competence and trust: a new road for logistics management Cross cultural management: an international journal, United Kingdom, v. 11, n. 3, p. 38-53, 2004. 
CANEN, A. G.; CANEN, A. Multicultural Leadership: the costs of its absence in organizational conflict management. International Journal of Conflict Management, United Kingdom v. 19, p. 4-19, 2008.

. A. Organizações multiculturais: logística na corporação globalizada. Rio de Janeiro: Ciência Moderna, 2005.

CARVALHO, D. E. Uma contribuição para a elaboração de mapas estratégicos: um estudo da aplicação do método de análise e estruturação de modelos (AEM). 2009. 138 f. Dissertação (Mestrado)-Programa de Pós Graduação em Administração, Universidade de São Paulo, São Paulo, 2009.

CORRÊA, A. C. O Balanced Scorecard como um sistema complexo adaptativo: uma abordagem quântica à estratégia. 2005. $361 \mathrm{f}$. Tese (Doutorado)-Faculdade de Engenharia de Produção, Universidade Federal de Santa Catarina, Florianópolis, 2005.

DERRIDA, J. Força de lei: o fundamento místico da autoridade. São Paulo: WMF: Martins Fontes, 2007.

FIGUEIREDO, A. L. A. Seleção e contratação de prestadores de serviços logísticos para uma empresa de mídia de jornal: um estudo de caso. 2007. Dissertação (Mestrado)-Pós-Graduação em Engenharia de Produção Industrial, Pontifícia Universidade Católica do Rio de Janeiro, Rio de Janeiro, 2007.

FISHER, R.; URY, W.; PATTON, B. Como chegar ao sim: negociação de acordos sem concessões. 2. ed. Rio de Janeiro: IMAGO, 2005.

FRAGA, V. F. Gestão pela formação humana: uma abordagem fenomenológica. Rio de Janeiro: Editora Impetus, 2003.

GONÇALVES, M. A. S. Teoria da ação comunicativa de habermas: possibilidades de uma ação educativa de cunho interdisciplinar na escola. Educação \& Sociedade, São Paulo, ano 20, n. 66, p.125-140, abr. 1999.

HOFSTEDE, G. Culturas e organizações: compreender a nossa programação mental. Lisboa: Silabo, 1997.

KAPLAN, R. S.; NORTON, D. P. A estratégia em ação: Balanced Scorecard. Rio de Janeiro: Campus, 1997.

Kaplan e Norton na prática. Rio de Janeiro: Elsevier, 2004a.

KAPLAN, R. S.; NORTON, D. P. Mapas estratégicos: Balanced Scorecard: convertendo ativos intangíveis em resultados tangíveis. Rio de Janeiro: Elsevier, $2004 \mathrm{~b}$. 
LIKERT, R.; LIKERT, J. G. Administração de conflitos: novas abordagens. São Paulo: McGraw-Hill, 1979.

MOITA LOPES, L. P. Sexualidades em sala de aula: discurso, desejo e teoria queer. In: MOREIRA, A. F.; CANDAU, V. M. (Org.). Multiculturalismo: diferenças culturais e práticas pedagógicas. Petrópolis: Vozes, 2008.

NIVEN, P. R. Balanced Scorecard passo a passo: elevando o desempenho e mantendo resultados. Rio de Janeiro: Qualitymark, 2007.

PAMPLONA, A. A. Reflexões para se pensar as diferenças: a experiência de uma escola pública municipal. 2009. 187 f. Dissertação (Mestrado)-Mestrado Profissional em Gestão do Patrimônio Cultural, Universidade Católica de Goiás, Goiânia, 2009.

PREEDY, M. et al. Gestão em educação: estratégias, qualidade e recursos. Porto Alegre: Artmed, 2006.

SEMPRINI, A. Multiculturalismo. Bauru: Edusc, 1999.

SILVA, T. T. Currículo e identidade social: territórios contestados. In: (Org.). Alienígenas na sala de aula: uma introdução aos estudos culturais em educação. Petrópolis: Vozes, 2009.

STÜHLER, G. D.; ASSIS, M. D. P. Relações interpessoais: construindo um clima institucional positivo na escola. In: CANEN, A.; SANTOS, A. R. (Org.). Educação multicultural: teoria e prática para professores e gestores em educação. Rio de Janeiro: Ciência Moderna, 2009.

TROMPENAARS, F. Nas ondas da cultura: como entender a diversidade cultural nos negócios. São Paulo: Educator, 1994.

VERGARA, S. C. Métodos de pesquisa em administração. 2. ed. São Paulo: Atlas, 2006.

Recebido em: 16/02/2011

Aceito para publicação em: 05/01/2012 